\title{
Adolescents Who Report Being Involved in Physical Fights in Mauritius: A Cross-Sectional Study of Socio-Demographic and Behavioral Correlates
}

\author{
Olumide Abiodun ${ }^{1}$, Michael Lowery Wilson ${ }^{1,2, *}$ and Masood Ali Shaikh ${ }^{1}$ \\ 1 ICT University, Cameroon Campus, 1 Avenue Dispensaire Messassi, Zoatoupsi, Yaoundé, Cameroon; \\ abiodun.olumide@ictuniversity.org (O.A.); masoodalishaikh@gmail.com (M.A.S.) \\ 2 Centre for Injury Prevention and Community Safety (CIPCS), PeerCorps Trust Fund, \\ 352/64 Makunganya Street, Co-Architecture Building, 4th Floor, P.O. Box 22499, Dar es Salaam, Tanzania \\ * Correspondence: michael.wilson@peercorpstrust.org
}

\section{check for} updates

Citation: Abiodun, O.; Lowery Wilson, M.; Shaikh, M.A. Adolescents Who Report Being Involved in Physical Fights in Mauritius: A Cross-Sectional Study of Socio-Demographic and Behavioral Correlates. Adolescents 2021, 1 , 151-158. https://doi.org/10.3390/ adolescents1020012

Academic Editors: Alan Apter and Wing-Hong Chui

Received: 19 February 2021

Accepted: 26 April 2021

Published: 6 May 2021

Publisher's Note: MDPI stays neutral with regard to jurisdictional claims in published maps and institutional affiliations.

Copyright: (c) 2021 by the authors. Licensee MDPI, Basel, Switzerland. This article is an open access article distributed under the terms and conditions of the Creative Commons Attribution (CC BY) license (https:// creativecommons.org/licenses/by/ $4.0 /)$.
Abstract: Background: violence among young people, including physical fighting, is a crucial global public health concern. There is a scarcity of evidence directed at understanding the prevalence and associated factors for physical fights among adolescents in Mauritius. This study aimed to examine the prevalence physical fighting in schools and the demographic characteristics that are associated with the phenomenon. Methods: we conducted a cross-sectional analysis of nationally representative data from Mauritius with the aim of examining the 12-month prevalence of physical fighting and frequencies of related individual and social-level characteristics. We further measured the association between physical violence and adolescent parameters using binary logistic regression analyses. Results: the participants were predominantly females (53.49\%) with a mean age of 14.91 (1.47) years. Within the preceding twelve months, $15.74 \%$ of the participants reported being involved in physical fights. Among other factors, the male gender $(\mathrm{OR}=2.6,95 \% \mathrm{CI}(1.87,3.62))$, food deprivation $(\mathrm{OR}=2.46,95 \% \mathrm{CI}(1.41,4.32))$, bullying victimization $(\mathrm{OR}=2.81,95 \% \mathrm{CI}(2.12,3.73))$, and cigarette use $(\mathrm{OR}=2.07,95 \% \mathrm{CI}(1.34,3.19))$ increased the likelihood of physical fighting. The other associated factors were loneliness $(\mathrm{OR}=1.65,95 \% \mathrm{CI}(1.11,2.43))$, physical activity $(\mathrm{OR}=1.52$, $95 \% \mathrm{CI}(1.09,2.12))$, early sexual debut $(\mathrm{OR}=2.15,95 \% \mathrm{CI}(1.17,3.95))$, and alcohol use $(\mathrm{OR}=1.56,95 \%$ CI $(1.11,2.21))$. Conclusions: physical violence is frequent among adolescents in Mauritius; however, a comparison with previous findings in similar sub-Saharan countries suggests a reducing trend. Advocates, policymakers, and other critical stakeholders need to consider the relevant demographic and behavioral factors in formulating strategies and designing public health interventions for the prevention and control of physical violence among adolescents.

Keywords: adolescents; violence; epidemiology; global health; mental health; behavioral health

\section{Introduction}

Violence among young people, including physical fighting, is an important concern of public health importance worldwide [1]. The prevalence of physical fighting among adolescents varies widely among studied high-income countries (HIC), from 13 to $32 \%$ among females and 37 to $69 \%$ among males [2]. Furthermore, the reporting of youth violence appears to be on the increase, being potentially related with campaigns tasked with increasing its awareness of the problem's severity in many HICs [3]. The economic reality of youth violence is also significant. Violence among young people is estimated to account for losses of as much as $4 \%$ of the Gross National Product (GNP) of many countries [4]. Available evidence also suggests that violence among adolescents is highly prevalent in low-and-middle-income countries (LMICs) [5]. The prevalence of adolescent physical fighting varied from 34.5 to $66.3 \%$ among six countries in the western pacific region in 2017, while the rates for Egypt (2006), Ghana (2004), and Namibia (2004) were $31 \%, 32 \%$, and $50.6 \%$, respectively [5-8]. 
Physical fighting contributes significantly to morbidity and mortality among the world's youth. Violence was ranked as the fourth leading cause of mortality among young people between 15 and 19 years old in 2013 [9]. Adolescents who are exposed to violence are significantly more likely to engage in unhealthy social behaviors, such as alcohol and drug abuse, as well as go on to be involved in violent and aggressive behaviors as adults $[6,7,10-12]$. Physical fighting is also associated with injuries, threats, intimidation, vulnerability, school absenteeism, and dropout [13,14].

In its 2014 technical report, the World Health Organization (WHO) observed that only one-third of the over 130 countries examined had implemented national-scale interventions to mitigate physical violence in schools. Therefore, the WHO called for a global commitment to violence prevention among all people, young and old, and for initiatives to combat violence [1]. Increasing research is directed towards understanding the risk and protective factors for physical fighting among young people as a basis for the development of preventive strategies. However, the available evidence is disproportionately from HICs, and are, therefore, not often generalizable $[3,5,10,15]$.

Empirical data on physical fighting among adolescents in the African, while available, region are largely limited to self-reported surveys of in-school adolescents [6]. While the limitations of such surveys include the inability to ascertain exposure to violence of those who do not attend school [7], they do provide useful adjuncts to estimating the burden within school settings. These existing studies also, where available, have tended to focus on the larger and mainly English-speaking regions of the African continent, as opposed to islands nations and those with other lingua francas, such as French.

Owing to the existing paucity of information that is related to youth violence within the smaller, less studied nations of the African region, we selected Mauritius to be the subject of a secondary analysis. In the present study, we aimed to examine the prevalence physical fighting in Mauritian schools as well as the demographic characteristics that are associated with the phenomenon. Thus, the findings are anticipated to provide potentially relevant information for the development of policy and strategy development targeted at the attenuation of violent behavior among school attending youth in the region.

\section{Methods}

\subsection{Sample}

The current study is an analysis of secondary data from the 2017 Republic of Mauritius contribution to the the Global School-based Health Survey (GSHS). The methodology for the GHSH was developed through a collaboration between the World Health Organization and the United States Centers for Disease Control (CDC). The detailed methods are available elsewhere http:/ / www.cdc.gov/gshs/ (accessed on 15 April 2021). The GSHS is a self-report survey of health-risk behaviors among school-attending adolescents. In the 2017 Mauritius GSHS, 3012 students in grades 8 to 12 were interviewed. With a 100\% school and $84 \%$ students' response rates, the survey had an overall response rate of $84 \%$. In the dataset, 14 cases had missing values for sex, while three had no record of age. In order to align with the designed-based analysis, we included all cases in our analysis. All of the data used in this study were publicly available at http:/ /www.cdc.gov/gshs/ (accessed on 15 April 2021).

\subsection{Measurements}

The outcome variable for our analysis, physical fighting, was assessed with one time in the GSHS: "During the past 12 months, how many times were you in a physical fight?" The possible responses to the item were, " 0 times", " 1 time", " 2 or 3 times", " 4 or 5 times", "6 or 7 times", "8 or 9 times", "10 or 11 times", or "12 or more times". We recoded this into a dichotomous variable. The participants who answered zero or one time were regarded as not having participated in physical fights $(\mathrm{N}=2542)$, while those who the others were deemed to have participated in physical fights $(\mathrm{N}=466)$, except for four respondents who had missing values for the item. Our analysis involved 13 individual and four social level 
independent variables. The individual variables are; age, sex, anxiety, suicide planning, loneliness, truancy, bullying victimization, physical activity, and sedentary lifestyle. The others are early sexual debut, alcohol use, marijuana use, and cigarette smoking. The social variables are food insecurity, the extent of the social network, the presence of helpful peers, and the presence of supportive parental figures. The choice of variables was based on findings of previous studies [16-18].

Table 1, below, contains a detailed description of these variables and the questionnaire items from which they were derived.

Table 1. The independent variables derivation from Mauritius, GSHS survey data 2017.

\begin{tabular}{|c|c|c|}
\hline Variable Name & Question & Coded as \\
\hline \multicolumn{3}{|l|}{ Individual level variables } \\
\hline How old are you? & 11-18 years (coded continuous) & Age \\
\hline What is your sex? & Male (1) Female (0) & Sex \\
\hline $\begin{array}{l}\text { During the past } 12 \text { months, how often have you been so } \\
\text { worried about something that you could not sleep at night? }\end{array}$ & $\begin{array}{l}\text { Most of the time/always (1) } \\
\text { Never/rarely/sometimes (0) }\end{array}$ & Anxiety \\
\hline During the past 12 months, how often have you felt lonely? & $\begin{array}{l}\text { Most of the time/always (1) } \\
\text { Never/rarely/sometimes (0) }\end{array}$ & Loneliness \\
\hline During the past 30 days, on how many days were you bullied? & 0 times $(0) 1$ or more times $(1)$ & Bullying \\
\hline $\begin{array}{l}\text { During the past } 30 \text { days, how many days did you miss classes } \\
\text { or school without permission? }\end{array}$ & $0-2$ times $(0) 3$ or more days $(1)$ & Truancy \\
\hline $\begin{array}{l}\text { During the past } 7 \text { days, on how many days were you } \\
\text { physically active for a total of at least } 60 \text { min per day? }\end{array}$ & 3 days or less ( 0$) 4$ days or more (1) & Physical activity \\
\hline $\begin{array}{l}\text { How much time do you spend during a typical or usual day } \\
\text { sitting and watching television, playing computer games, } \\
\text { talking with friends, or doing other sitting activities? }\end{array}$ & $2 \mathrm{~h}$ or less (0) $3 \mathrm{~h}$ or more (1) & Sedentary \\
\hline $\begin{array}{l}\text { During the past } 12 \text { months, did you make a plan about how } \\
\text { you would attempt suicide? }\end{array}$ & Yes (1) No (0) & Suicide Plan \\
\hline $\begin{array}{l}\text { How old were you when you had sexual Intercourse for the } \\
\text { first time? }\end{array}$ & $\begin{array}{l}\text { Never had sex or had after age } 14(0) \\
\text { Had sex at age } 14 \text { or earlier }(1)\end{array}$ & Early sexual debut \\
\hline $\begin{array}{c}\text { During the past } 30 \text { days, on how many days did you have at } \\
\text { least one drink containing alcohol? }\end{array}$ & 0 days (0) 1 or more days $(1)$ & Alcohol use \\
\hline $\begin{array}{l}\text { During the past } 30 \text { days, how many times have you used } \\
\text { marijuana (also called dagga, weed, boom, cannibus, stop, } \\
\text { grass, pipt, stop, and joint)? }\end{array}$ & 0 days $(0) 1$ or more days $(1)$ & Marijuana use \\
\hline $\begin{array}{c}\text { During the past } 30 \text { days, on how many days did you smoke } \\
\text { cigarettes? }\end{array}$ & 0 days $(0) 1$ or more days $(1)$ & Cigarette smoking \\
\hline \multicolumn{3}{|l|}{ Social level variables } \\
\hline $\begin{array}{l}\text { During the past } 30 \text { days, how often did your parents or } \\
\text { guardians understand your problems and worries? }\end{array}$ & $\begin{array}{l}\text { Most of the time/always (1) } \\
\text { Never/rarely/sometimes (0) }\end{array}$ & $\begin{array}{l}\text { Supportive parental } \\
\text { figures }\end{array}$ \\
\hline $\begin{array}{l}\text { During the past } 30 \text { days, how often were most of the students } \\
\text { in your school kind and helpful? }\end{array}$ & $\begin{array}{l}\text { Most of the time/always (1) } \\
\text { Never/rarely/sometimes (0) }\end{array}$ & Helpful peers \\
\hline How many close friends do you have? & $\begin{array}{l}0 \text { close friends ( } 0) 1 \text { close friends ( } 1 \text { ) } \\
2 \text { close friends (2) } 3+\text { close friends ( } 3 \text { ) } \\
\text { (coded continuous) }\end{array}$ & Close friends \\
\hline $\begin{array}{l}\text { During the past } 30 \text { days, how often did you go hungry } \\
\text { because there was not enough food in your home? }\end{array}$ & $\begin{array}{l}\text { Most of the time/always (1) } \\
\text { Never/rarely/sometimes (0) }\end{array}$ & Food insecurity \\
\hline
\end{tabular}




\subsection{Statistical Analysis}

The current study used the Stata 16 (StataCorp, 2019) for all analyses. First, we examined the frequency distribution of the independent variables in the dataset. Second, we compared the distribution of the variables with respect to the dichotomous outcome variable (physical fighting). Subsequently, we assessed the statistically significant relationship between the outcome and independent variables. We used the survey version of the chi-squared test, a design-adjusted version of the Pearson's chi-square test, for categorical variables, and the design-adjusted version of the $t$-test for discrete variables (number of friends and age of participants). Afterward, we created two binary logistic regression models to assess the ability of the independent $t$ variables to predict the involvement of the participants in physical fighting. We adjusted the first model for age and sex, but included all of the variables that were statistically significant at $p=0.05$ in the second model. We assessed multicollinearity among the independent variables and then tested the Goodnessof-it of the final model. The Odds ratio is reported as the measure of association between the independent and outcome variables. We present the adjusted (aOR) and unadjusted (OR) odds ratio with the respective $95 \%$ confidence intervals. All proportions-expressed in percentages-are weighted.

\section{Results}

Within the recall period, $15.74 \%(n=466)$ of the participants reported being involved in two or more physical fights.

Table 2 shows the weighted distribution of all selected factors, according to the involvement in physical fights status, and their statistical significance. The bivariate analyses show that, out of seventeen attributes, three, i.e., age, number of close friends, and having helpful peers, were not statistically significantly associated with involvement in physical fights in the twelve months preceding the survey.

Table 2. The distribution of selected factors according to categories of physical fighting among school-attending adolescents in Mauritius, GSHS 2017.

\begin{tabular}{cccc}
\hline Variable & No Physical Fights $(\mathbf{n}=\mathbf{2 5 4 2})$ & Physical Fights $(\mathbf{n}=\mathbf{4 6 6})$ & $p$-Value \\
\hline Age (SD) & $14.95(1.47)$ & $14.72(1.49)$ & 0.087 \\
Close friends (SD) & $2.36(0.99)$ & $2.25(1.10)$ & 0.177 \\
Sex (male) & 42.41 & 68.84 & $<0.001$ \\
Anxiety & 8.53 & 13.99 & 0.004 \\
Loneliness & 9.2 & 18.64 & $<0.001$ \\
Food deprivation & 6.51 & 12.98 & 0.001 \\
Bullying victimization & 19.60 & 46.46 & $<0.001$ \\
Truancy & 7.26 & 19.56 & $<0.001$ \\
Physical Activity & 34.19 & 43.33 & 0.008 \\
Sedentary & 38.27 & 50.67 & $<0.001$ \\
Supportive parental figures & 42.43 & 31.58 & 0.003 \\
Helpful peers & 36.76 & 31.99 & 0.104 \\
Suicide planning & 12.95 & 23.57 & 0.002 \\
Early sexual debut & 5.87 & 20.16 & $<0.001$ \\
Alcohol use & 23.00 & 45.85 & $<0.001$ \\
Marijuana use & 4.48 & 15.62 & $<0.001$ \\
Cigarette smoking & 13.94 & 40.92 & $<0.001$ \\
\hline
\end{tabular}

All variables are expressed as proportions (in \%) with the exception of age and close friends (mean and standard deviation).

Table 3 shows the age and sex adjusted analysis for all the attributes studied. The sex and age variables were each, adjusted for the other. With the exception of age, physical activity, and having helpful peers, all other attributes were found to be statistically significantly associated with the involvement in physical fighting. 
Table 3. The distribution of selected factors according to categories of physical fighting among school-attending adolescents in Mauritius, GSHS 2017.

\begin{tabular}{cccc}
\hline Variable & Adjusted OR & $\mathbf{9 5} \% \mathbf{C I}$ & $p$-Value \\
\hline Age (SD) & 0.9 & $0.79-1.02$ & 0.086 \\
Close friends (SD) & 0.88 & $0.77-0.99$ & 0.047 \\
Sex (male) & 3.02 & $1.96-4.64$ & $<0.001$ \\
Anxiety & 2.02 & $1.42-2.87$ & 0.001 \\
Loneliness & 2.64 & $2.03-3.42$ & $<0.001$ \\
Food deprivation & 2.66 & $1.76-4.00$ & $<0.001$ \\
Bullying victimization & 3.34 & $2.72-4.11$ & $<0.001$ \\
Truancy & 2.51 & $1.66-3.80$ & $<0.001$ \\
Physical Activity & 1.23 & $0.95-1.58$ & 0.105 \\
Sedentary & 1.84 & $1.40-2.41$ & $<0.001$ \\
Supportive parental figures & 0.62 & $0.47-0.82$ & 0.002 \\
Helpful peers & 0.89 & $0.72-1.09$ & 0.245 \\
Suicide planning & 2.56 & $1.66-3.97$ & $<0.001$ \\
Early sexual debut & 3.30 & $2.40-4.54$ & $<0.001$ \\
Alcohol use & 3.35 & $2.73-4.11$ & $<0.001$ \\
Marijuana use & 3.23 & $2.21-4.73$ & $<0.001$ \\
Cigarette smoking & 4.16 & $3.26-5.31$ & $<0.001$ \\
\hline
\end{tabular}

OR, Odds Ratio; $95 \%$ CI, 95\% Confidence Interval. All estimates are adjusted for age and sex; age; or sex.

Table 4 providest the results of final multivariable model, i.e., after adjusting for all of the covariates that were found to be statistically significant in the bivariate analysis. Out of the fourteen attributes, six i.e., anxiety, truancy, sedentary lifestyle, supportive parental figures, suicide planning, and marijuana use were not found to be statistically significantly associated with having been involved in physical fights at $p<0.05$; while, at the $p$-value of $<0.01$, only sex, food deprivation, bullying victimization, and cigarette use in the past 30 days were found to be statistically significant. The goodness-of-fit test revealed that this was a good multivariate logistic model for physical fighting among the sample population ([F: 9, 8] 0.27; $p$-value: 0.9661).

Table 4. Outcomes of multivariate analysis of variables associated with physical fighting among school-attending adolescents in Mauritius, GSHS 2017.

\begin{tabular}{cccc}
\hline Variable & Adjusted OR & $\mathbf{9 5 \%} \mathbf{C I}$ & $p$-Value \\
\hline Sex & 2.60 & $1.87-3.62$ & $<0.001$ \\
Anxiety & 1.03 & $0.58-1.83$ & 0.912 \\
Loneliness & 1.65 & $1.11-2.43$ & 0.015 \\
Food deprivation & 2.46 & $1.41-4.32$ & 0.004 \\
Bullying victimization & 2.81 & $2.12-3.73$ & $<0.001$ \\
Truancy & 1.22 & $0.74-2.03$ & 0.410 \\
Physical Activity & 1.52 & $1.09-2.12$ & 0.018 \\
Sedentary & 1.19 & $0.82-1.73$ & 0.334 \\
Supportive parental figures & 0.88 & $0.65-1.20$ & 0.409 \\
Suicide planning & 1.35 & $0.90-2.04$ & 0.137 \\
Early sexual debut & 2.15 & $1.17-3.95$ & 0.017 \\
Alcohol use & 1.56 & $1.11-2.21$ & 0.014 \\
Marijuana use & 0.83 & $0.31-2.20$ & 0.687 \\
Cigarette smoking & 2.07 & $1.34-3.19$ & 0.003 \\
\hline
\end{tabular}

Only those factors that were found to be statistically significant in bivariate analysis were used in this model. CI: Confidence Interval. All of the estimates are adjusted for all variables listed in the table.

\section{Discussion}

The current study found that $15.74 \%$ of the participants had engaged in two or more physical fights within the year prior to being surveyed. This rate is lower than that of the physical fighting behavior reported in other African region countries, which ranged from $31 \%$ to $50.6 \%$ [6-8]. This finding was the result of the analysis of a more recent dataset when 
compared to the other reports of data, which were about ten years older. Additionally, the prevalence of physical fighting in our study was lower than the rates in Southwest Pacific countries, North America, and Europe [2,10,15], but comparable to those from Southeast Asia [13,19-22].

The current study found that being male was significantly associated with increased physical fighting behavior. Previous studies have had divergent findings concerning the relationship between gender and adolescent violence. Whereas, most studies from Asia and Africa found that boys have a higher risk of exposure to violence [7,13,19,22,23], reports from the Western Pacific region, Europe, and the US report the opposite [5,10,24]. However, the findings of an investigation among Ghanaian adolescents showed no relationship between gender and involvement in physical fighting [8]. Additionally, bullying victimization and food deprivation were associated with physical fights in this study. This finding is similar to that of others $[7,8,13]$. Bullying, hunger, and truancy are likely related to poor mental health [25], which may underline the tendency to engage in physical fighting. This relationship will benefit from further exploration, especially mixed-methods research, in order to better understand the relationship between these factors. Truancy was not found to be associated with physical violence in the present study. The association between cigarette smoking and physical fighting in the current research was largely congruent with other studies $[10,15,19]$, and it strengthens previous reporting on the relationship between negative peer behaviors and physical fighting among school-based adolescents [8]. Additionally, as in other studies $[8,10,15]$, alcohol consumption was associated with physical fights in our study in the context of a high prevalence of alcohol consumption among the participants. Alcohol misuse, abuse, and the resulting negative life experiences predict physical fighting in both high-income and low-and-middle-income countries, as reported elsewhere [8].

The present study found that loneliness in Mauritius was associated with physical fighting, like other authors found among Malaysian and Pakistani adolescents [13,19], but suicide planning was not. Additionally, physical activity was related to adolescent physical violence, while a sedentary lifestyle was not. There is a paucity of evidence concerning the relationship between physical activity or a sedentary lifestyle and physical fighting, but the available data demonstrate a consistent association $[7,26,27]$. Future research should focus on determining the levels of physical activity that are predictive of physical violence. The finding of an association between early sexual debut and physical fighting corroborates those of other authors $[28,29]$.

Our study did not identify any protective factors for physical fighting among adolescents in Mauritius. Other studies have highlighted protective factors to include supportive school environments and the pressure of school work [8], close friends [13], helpful close friends [7], parental support [7,8,24], and access to increased wealth [3]. Although some other studies have found an absence of association between some of the protective factors and physical fighting $[13,23]$, the lack of statistically significant protective factors in our study underlines the need for further research into the subject matter.

The present study contributes to the body of knowledge concerning adolescent risk and protective factors for physical fighting. The similarities and variations that were observed relative to findings from other countries suggest that adolescent physical violence is a universal issue among adolescents, and it results from an interplay between various common socio-demographic, behavioral, and environmental adolescent characteristics. However, there may be contextual factors that alter the mechanisms that underlie adolescent physical fighting, causing variations in risk and protective factors across different settings. Some of the risk factors for physical violence in our study are modifiable and offer specific opportunities for interventions to mitigate interpersonal violence among adolescents.

\section{Strengths and Limitations}

This study contributes to the limited body of knowledge regarding adolescent interpersonal violence in the African region. The use of population-based sampling, standardized 
methodology, and validated tools for data collection make our findings amenable to direct comparison across countries and regions. The sample size is large and representative of all in-school adolescents in Mauritius. Therefore, our results are likely to be valid and representative of the underlying population. However, the readers should consider a few limitations in interpreting the findings. First, the data were obtained through self-reporting and are, therefore, prone to misreporting. Misreporting can be intentional due to the sensitivity and social desirability of the issue under investigation, which results in the regression of the estimates towards null values. Consequently, this leads to an underestimation of the size of the association between the outcome variable and associated factors. Misreporting might also be unintentional in the case of failure of recall or misunderstanding of the questions. Secondly, the data collection was from in-school adolescents, and the findings would not be generalizable to all adolescents in Mauritius, because in and out-of-school adolescents often differ significantly. Thirdly, the study design was cross-sectional. Hence, readers should not ascribe causal interpretations to the associations between physical fighting and related factors. Finally, the GSHS obtained data regarding physical violence without considering the severity fights or whether the adolescents were the aggressors or victims.

\section{Conclusions}

The present research provides some insight into adolescent physical fighting in the context of a scarcity of data concerning its epidemiology, as obtained in Mauritius. Physical violence is frequent among adolescents in Mauritius, although, comparison with previous findings in similar sub-Saharan countries suggests a reducing trend. Future studies should monitor the trend of physical fighting over time. There exists a clustering of physical violence with modifiable and non-modifiable socio-demographic and behavioral factors. Advocates, policymakers, and other critical stakeholders need to consider these associations in formulating strategies and designing public health interventions for the prevention and control of physical violence among adolescents. School-based interventions that incorporate the pertinent risk factors are likely to be very successful.

Author Contributions: Conceptualization, M.A.S.; methodology, M.A.S. and M.L.W.; validation, O.A., and M.L.W.; formal analysis, M.A.S.; writing—original draft preparation, All; writing—review and editing, All. All authors have read and agreed to the published version of the manuscript.

Funding: This research received no external funding.

Institutional Review Board Statement: IRB was not required as the data are publicly available in anonymized form.

Informed Consent Statement: Informed consent was not required for the conduct of this study as the data are publicly available in anonymized form.

Data Availability Statement: All of the data usedin this study were publicly available at http: //www.cdc.gov/gshs/ (accessed on 15 April 2021).

Conflicts of Interest: The authors declare no conflict of interest.

\section{References}

1. World Health Organization. Global Status Report on Violence Prevention 2014; World Health Organization: Geneva, Switzerland, 2014.

2. Pickett, W.; Craig, W.; Harel, Y.; Cunningham, J.; Simpson, K.; Molcho, M.; Mazur, J.; Dostaler, S.; Overpeck, M.D.; Currie, C.E.; et al. Cross-national study of fighting and weapon carrying as determinants of adolescent injury. Pediatrics 2005, 116, e855-e863. [CrossRef]

3. Pickett, W.; Molcho, M.; Elgar, F.J.; Brooks, F.; De Looze, M.; Rathmann, K.; Ter Bogt, T.F.; Gabhainn, S.N.; Sigmundová, D.; de Matos, M.G.; et al. Trends and socioeconomic correlates of adolescent physical fighting in 30 countries. Pediatrics 2013, 131, e18-e26. [CrossRef]

4. Krug, E.G.; Mercy, J.A.; Dahlberg, L.L.; Zwi, A.B. The world report on violence and health. Lancet 2002, 360, 1083-1088. [CrossRef]

5. Yang, L.; Zhang, Y.; Xi, B.; Bovet, P. Physical fighting and associated factors among adolescents aged 13-15 years in six Western Pacific countries. Int. J. Environ. Res. Public Health 2017, 14, 1427. [CrossRef] [PubMed] 
6. Rudatsikira, E.; Siziya, S.; Kazembe, L.N.; Muula, A.S. Prevalence and associated factors of physical fighting among school-going adolescents in Namibia. Ann. Gen. Psychiatry 2007, 6, 18. [CrossRef] [PubMed]

7. Celedonia, K.L.; Wilson, M.L.; El Gammal, H.A.; Hagras, A.M. Physical fighting among Egyptian adolescents: Social and demographic correlates among a nationally representative sample. Peer] 2013, 1, e125. [CrossRef] [PubMed]

8. Acquah, E.O.; Lloyd, J.K.; Davis, L.; Wilson, M.L. Adolescent physical fighting in Ghana, their demographic and social characteristics. Soc. Sci. 2014, 3, 227-241. [CrossRef]

9. Mokdad, A.H.; Forouzanfar, M.H.; Daoud, F.; Mokdad, A.A.; El Bcheraoui, C.; Moradi-Lakeh, M.; Kyu, H.H.; Barber, R.M.; Wagner, J.; Cercy, K.; et al. Global burden of diseases, injuries, and risk factors for young people's health during 1990-2013: A systematic analysis for the Global Burden of Disease Study 2013. Lancet 2016, 387, 2383-2401. [CrossRef]

10. Fraga, S.; Ramos, E.; Dias, S.; Barros, H. Physical fighting among school-going Portuguese adolescents: Social and behavioural correlates. Prev. Med. 2011, 52, 401-404. [CrossRef]

11. Reingle, J.M.; Jennings, W.G.; Maldonado-Molina, M.M. Risk and protective factors for trajectories of violent delinquency among a nationally representative sample of early adolescents. Youth Violence Juv. Justice 2012, 10, 261-277. [CrossRef]

12. Molero Jurado, M.D.M.; Pérez-Fuentes, M.D.C.; Simón Márquez, M.D.M.; Barragán Martín, A.B.; Sisto, M.; Gázquez Linares, J.J. Relationship Between Impulsivity, Sensation-Seeking, and Drug Use in Aggressors and Victims of Violence. Front. Psychol. 2020, 11. [CrossRef]

13. Shaikh, M.A.; Abio, A.; Celedonia, K.L.; Lowery Wilson, M. Physical fighting among school-attending adolescents in Pakistan: Associated factors and contextual influences. Int. J. Environ. Res. Public Health 2019, 16, 5039. [CrossRef] [PubMed]

14. Pérez-Fuentes, M.D.C.; Molero Jurado, M.D.M.; Barragán Martín, A.B.; Gázquez Linares, J.J. Profiles of Violence and Alcohol and Tobacco Use in Relation to Impulsivity: Sustainable Consumption in Adolescents. Sustainability 2019, 11, 651. [CrossRef]

15. Rudatsikira, E.; Muula, A.S.; Siziya, S. Variables associated with physical fighting among US high-school students. Clin. Pract. Epidemiol. Ment. Health 2008, 4, 16. [CrossRef]

16. Davis, L.E.; Abio, A.; Wilson, M.L.; Shaikh, M.A. Extent, patterns and demographic correlates for physical fighting among school-attending adolescents in Namibia: Examination of the 2013 Global School-based Health Survey. PeerJ 2020, 8, e9075. [CrossRef]

17. Omer, M.; Shaikh, M.A.; Stiller, M.; Lowery Wilson, M. Physical Fighting among School-Attending Adolescents in El Salvador: An Examination of the 2013 Global School-Based Health Survey. Int. J. Environ. Res. Public Health 2020, 17, 1248. [CrossRef]

18. Abio, A.; Wilburn, J.K.; Shaikh, M.A.; Wilson, M.L. School Violence Among a Nationally Representative Sample of Adolescents in Chile. Front. Public Health 2020, 8, 46. [CrossRef]

19. Lee, L.K.; Chen, P.C.; Lee, K.K.; Kaur, J. Violence-related behaviours among Malaysian adolescents: A cross sectional survey among secondary school students in Negeri Sembilan. Ann.-Acad. Med. Singap. 2007, 36, 169.

20. Sam-Angsri, N.; Assanangkornchai, S.; Pattanasattayawong, U.; Muekthong, A. Health-risk behaviors among high-school students in southern Thailand. J. Med. Assoc. Thail. 2011, 93, 1075.

21. Sirirassamee, T.; Sirirassamee, B. Health risk behavior among Thai youth: National survey 2013. Asia Pac. J. Public Health 2015, 27, 76-84. [CrossRef]

22. Ruangkanchanasetr, S.; Plitponkarnpim, A.; Hetrakul, P.; Kongsakon, R. Youth risk behavior survey: Bangkok, Thailand. J. Adolesc. Health 2005, 36, 227-235. [CrossRef] [PubMed]

23. Mat Hussin, S.F.; Abd Aziz, N.S.; Hasim, H.; Sahril, N. Prevalence and factors associated with physical fighting among Malaysian adolescents. Asia Pac. J. Public Health 2014, 26, 108S-115S. [CrossRef]

24. Graves, K.N. Not always sugar and spice: Expanding theoretical and functional explanations for why females aggress. Aggress. Violent Behav. 2007, 12, 131-140. [CrossRef]

25. Wilson, M.L.; Celedonia, K.L.; Kamala, B.A. Patterns, characteristics, and correlates of adolescent bully-victims in urban Tanzania. Soc. Sci. 2013, 2, 234-246. [CrossRef]

26. Iannotti, R.J.; Janssen, I.; Haug, E.; Kololo, H.; Annaheim, B.; Borraccino, A. Interrelationships of adolescent physical activity, screen-based sedentary behaviour, and social and psychological health. Int. J. Public Health 2009, 54, 191-198. [CrossRef] [PubMed]

27. Morris, R.G.; Johnson, M.C. Sedentary activities, peer behavior, and delinquency among American youth. Crime Delinq. 2014, 60, 939-968. [CrossRef]

28. Peltzer, K.; Pengpid, S. Physical fighting and social correlates among in-school adolescents in the Caribbean. Mediterr. J. Soc. Sci. 2014, 5, 531-531. [CrossRef]

29. Kuzman, M.; Pavić Šimetin, I.; Pejnović Franelić, I. Early sexual intercourse and risk factors in Croatian adolescents. Coll. Antropol. 2007, 31, 121-130. [PubMed] 